\title{
Characterization and Application of Aluminum Dross as Catalyst in Pyrolysis of Waste Cooking Oil
}

\author{
Faten Hameed Kamil' ${ }^{1}$, Ali Salmiaton ${ }^{1,2^{*}}$, Raja Mohamad Hafriz Raja Shahruzzaman ${ }^{1}$, R. \\ Omar ${ }^{1}$, Abdulkareem Ghassan Alsultsan ${ }^{2}$ \\ ${ }^{1}$ Department of Chemical and Environmental Engineering, Faculty of Engineering, Universiti Putra \\ Malaysia, 43400 UPM Serdang, Selangor, Malaysia \\ ${ }^{2}$ Catalysis Science and Technology Research Center (Putra Cat), Universiti Putra Malaysia, 43400 \\ UPM Serdang, Selangor, Malaysia
}

Received: 20th June 2016; Revised: 28th October 2016; Accepted: $13^{\text {rd }}$ November 2016

\section{Abstract}

Aluminium dross, a waste material produced by dissolution of aluminum scrap, was characterized physically and chemically by various analysis techniques for a potential to be used as catalyst. Using catalyst from waste materials reduced the cost for synthesizing of new catalyst. An efficient catalyst derived from industrial solid waste was modified by acid washing for using in a pyrolysis of waste cooking oil. The modification of aluminum dross resulted in increased surface area (from 0.96 to 68.24 $\mathrm{m}^{2} / \mathrm{g}$ ), acidity (from 315 to $748 \mu \mathrm{mol} / \mathrm{g}$ ) and thermal stability. Pyrolysis waste cooking oil was used to test the performance of aluminum dross as catalyst before and after modification. The product analysis showed a better result than the unmodified material based on increased yield of bio-oil and improved selectivity. Copyright (C) 2017 BCREC GROUP. All rights reserved

Keywords: Al dross; Thermal activation; Chemical activation; Pyrolysis waste cooking oil

How to Cite: Kamil, F.H., Salmiaton, A., Shahruzzaman, R.M.H.R., Omar, R., Alsultsan, A.G. (2017). Characterization and Application of Aluminum Dross as Catalyst in Pyrolysis of Waste Cooking Oil. Bulletin of Chemical Reaction Engineering \& Catalysis, 12 (1): 81-88 (doi:10.9767/bcrec.12.1.557.81-88)

Permalink/DOI: http://dx.doi.org/10.9767/bcrec.12.3.557.81-88

\section{Introduction}

Recently, the researchers have applied catalytic materials which derived from waste materials. In some processes, using catalyst can pose largest monetary cost so that the efforts forward to search catalyst from waste materials. In addition, sustainability has become a sign and significant factor in modern society. Waste materials not only grant alternative renewable source, but also provide a resource to synthesize catalysts [1].

* Corresponding Author.

E-mail:mie@upm.edu.my

Telp.: +603-89466297 Fax.: +603-86567120
Aluminum dross is by-product that is formed after aluminum liquefied in a customary purging or reusing procedures. Around 5 million tons of aluminum dross is generated every year around the world [2]. Substantial amounts of the dross are discarded in landfills poisoning health, natural and security peril issues in light of its poisonous quality and high combustibility. On the other hand, recycling 1 $\mathrm{kg}$ of aluminum waste save about $4 \mathrm{~kg}$ of bauxite, $2 \mathrm{~kg}$ of chemicals, and $7.5 \mathrm{kWh}$ of electricity [3]. Aluminum (Al) dross can be classified as three types namely white, black and salt cake, depending on the amount of aluminum present and the morphology of the wastes [4]. The main components of the dross are metallic alumi- 
num, aluminum oxides, aluminum chlorides and oxide of transition metals [2]. Therefore, $\mathrm{Al}$ dross considers as valuable material and there is much legitimacy if the dross that is shaped could be "reused" as an engineering item for particular applications.

Various studies have reported on the application of dross as an alternative material of $\mathrm{Al}$ for the preparation of catalytically active materials. Balakrishnan et al. [5] reported that zeotype $\mathrm{AlPO}_{4}{ }^{-5}$ was synthesized by the reaction of dross with phosphoric acid. Kim et al. [6] prepared $\mathrm{CrAPO}^{-5}$ (the chromium-containing analogue of $\mathrm{AlPO}_{4^{-5}}$ ) by using $\mathrm{Al}$ dross and identical properties were obtained with sample prepared by $\mathrm{Al}(\mathrm{OH})_{3}$. Das et al. [7] produced ńalumina from waste $\mathrm{Al}$ dross by leaching, hydrolyzing and calcination. In short, $\mathrm{Al}$ dross can be utilized as an alternative material of $\mathrm{Al}$ for preparation of the catalysts.

Pyrolysis is an effective and easy method for bio-fuel production. Kerosene, gasoline and diesel can be produced from catalytic pyrolysis in faster manner [8]. Using industrial waste as catalyst and utilize it to enhance the pyrolysis process can be considered as promising technologies in reducing the amount of waste generated from human activities and industrial processes. Bauxite which considers a rock consisting essentially of one or more aluminum hydroxide minerals has been tested as catalyst for catalytic cracking of soybean oil. The product generated showed better results than thermal cracking due to low quantity of acid present in the bio-oil. The presence of catalyst increase decarboxylation reaction of the carboxylic acids formed in primary cracking [9]. Red mud was used in pyrolysis of hemp-seed to produce biooil. The red mud was used after going through reduction process by acetic acid and formic acid. The reduced red mud upgraded bio-oil because the product consists of fewer carbonylcontaining and polar oxygenated compounds with more saturated hydrocarbon [10]. Blast furnace slag (BFS) was used in pyrolysis of waste sunflower oil. The product was rich with paraffinic content and lower naphthenic content [11].

Based on reported literatures, $\mathrm{Al}$ dross which is a waste material producing from aluminum processing still have value added materials that can be either recovered or treated using various techniques and have a potential to be used as catalyst. Instead of just disposed of, $\mathrm{Al}$ dross will be used as a raw material for this study. Detailed characterization of the $\mathrm{Al}$ dross will be performed. Modification of the $\mathrm{Al}$ dross for potential use as catalyst will also be con- ducted, and finally utilization of the $\mathrm{Al}$ dross in a pyrolysis of waste cooking oil for catalytic performance evaluation before and after modification process will be executed.

\section{Material and Method}

\subsection{Materials}

$\mathrm{Al}$ dross used in this study was supplied from Malaysian recycling company. Hydrochloric acid $(\mathrm{HCl})$ with $37 \%$ purity was obtained from R\&M Company. Waste cooking oil, which generated after frying vegetables, chicken, and meat, collected from residential area, was used for pyrolysis reaction. The oil was centrifuged at $6000 \mathrm{rpm}$ for $30 \mathrm{~min}$ and was then filtered to remove food residue. The oil obtained from centrifuging was used directly without further purification.

\subsection{Procedure}

For catalyst preparation, the sample was sieved to remove coarse and foreign particles and then ground by ball mill grinder for 1.5h. After that, the sieved ground sample was passed through a $300 \mu \mathrm{m}$ sieve. The method used to activate the sample of $\mathrm{Al}$ dross includes the followings: firstly; calcination in tubular furnace at $700{ }^{\circ} \mathrm{C}$ with heating rate $10{ }^{\circ} \mathrm{C} / \mathrm{min}$ for 5 hours. For acid washing treatment, $5 \mathrm{~g}$ sample was immersed into the solution prepared from $20 \mathrm{~mL} \mathrm{HCl}$ with $80 \mathrm{~mL} \mathrm{H}_{2} \mathrm{O}$ with continuous stirring conditions at room temperature for $3 \mathrm{~h}$. The acid washed sample was then filtered and washed with deionized water until the $\mathrm{pH}$ value of the washing water was neutral. The sample was dried by an oven (Memmert, model EU-200) at $100{ }^{\circ} \mathrm{C}$ for $24 \mathrm{~h}$ and then subjected to the calcination process by using tubular furnace at $600{ }^{\circ} \mathrm{C}$ for $3 \mathrm{~h}$ at heating rate of $10^{\circ} \mathrm{C} / \mathrm{min}$.

The pyrolysis of waste cooking oil was performed to test the activity of material as catalyst. Pyrolysis reactions were carried out in a fractionated cracking system as shown in Figure 1. The round flask waste was heated using stirring mantle (Misung Scientific Co. Ltd., model MS300). The reaction temperatures of $390-420{ }^{\circ} \mathrm{C}$ were chosen for batch cracking. The round flask was loaded with $150 \mathrm{~g}$ of waste of cooking oil. Then $5 \%$ catalyst was added to the oil. The mixture in the flask was then purged with nitrogen for oxygen free environment and heated to reaction temperature with heating rate at $20{ }^{\circ} \mathrm{C} / \mathrm{min}$. The liquid products were collected in a glass trap (receiving flask). The run period was kept $30 \mathrm{~min}$. At the end of experi- 
ments, the respective amount of the liquid and residual oil-coke were measured. The yield was calculated from Equation (1) and selectivity of carbon number was determined by comparing the peak area of obtained spectra with the peak area of the standard using Equation (2) [12, 13]. In order to confirm the reproducibility of the results, the experiments were conducted for three times.

Yield $(\%)=\frac{\text { pyrolysisoil product }}{\text { feed }} \times 100 \%$

Selectivit $(\%)=\frac{\text { Area of the desired product }}{\text { Total area of the product }} \times 100 \%$

\subsection{Characterization of catalyst}

To examine the changes that happen to $\mathrm{Al}$ dross, the unmodified and modified material were characterized using various characterization techniques. Chemical composition of the unmodifed and modified material was conducted using X-ray fluorescence spectroscopy (model Philips PWI 404). The specific surface area and pore volume were measured by Brun-

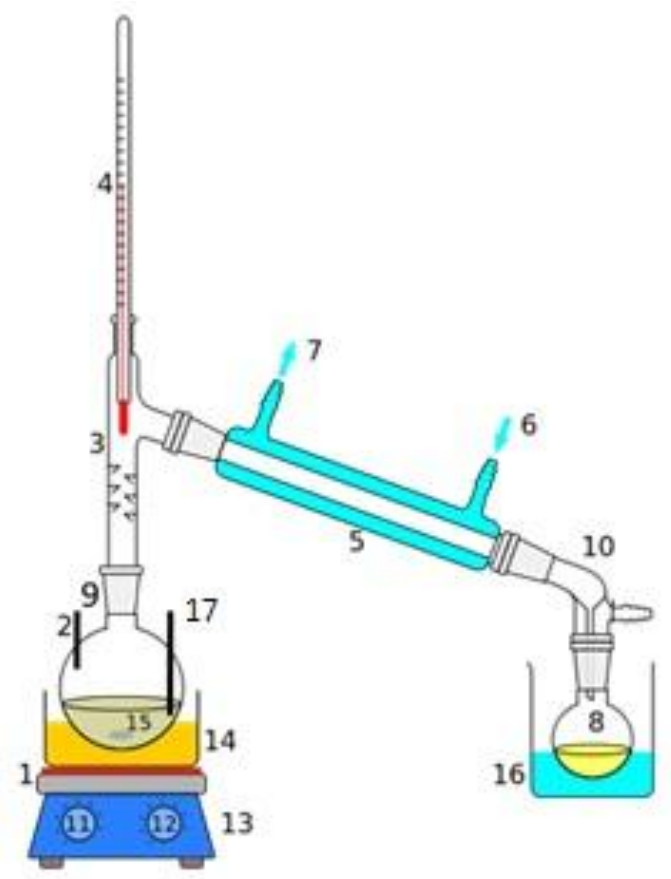

Figure 1. System used in the cracking process: 1: A heating device 2: Nitrogen gas inlet 3: Still head 4: Thermometer 5: Condenser 6: Cooling water in 7: Cooling water out 8: Distillate/receiving flask 9: Still pot 10: Still receiver 11: Heat control 12: Stirrer speed control 13: Stirrer/heat plate 14: Heating (sand) bath 15: mechanical stirrer 16: Cooling bath 17: Thermocouple.
auer-Emmett-Teller (BET) apparatus (Quantachrome, model Atosorb-1, USA). The thermogravimetric study was performed by using a thermogravimetric analyzer (model Mettler Toledo, TGA/SDT851, USA). The morphology of the material was investigated using SEM instrument (HITACHI, S-3400N, JAPAN). Temperature programmed desorption using $\mathrm{NH}_{3}$ (TPD-NH ) was utilized to measure the acidity of the catalyst (Thermo Finnigan, model TPDRO 1100 series).

\subsection{Characterization of bio-oil}

The functional groups of bio-oil was determined by Fourier Transform Infrared Absorption (FTIR) spectra instrument (model PerkinElmer 100 series, USA). In addition, the bio-oil products were quantitatively identified using alkane standards $\left(\mathrm{C}_{7}-\mathrm{C}_{20}\right)$, obtained from Sigma Aldrich. The analyses of cracking products were quantified using gas chromatography (Shimadzu GC-1413). The column used was a HP-5 capillary column $(32 \mathrm{~m} \times 0.25 \mathrm{~mm}$ and 0.25 thicknesses) with flame ionization detector (FID) operating at $300{ }^{\circ} \mathrm{C}$. The bio-oil product was diluted with $\mathrm{GC}$ grade $\mathrm{n}$-hexane before injection for the yield analysis. The injector temperature was $300{ }^{\circ} \mathrm{C}$, and the injector split ratio was set to $10: 1$. The flow rate of the $\mathrm{N}_{2}$ carrier gas was $1 \mathrm{~mL} / \mathrm{min}$. The oven temperature was programmed to hold at $50{ }^{\circ} \mathrm{C}$ for 6 min, then ramp at $7{ }^{\circ} \mathrm{C} / \mathrm{min}$ to $270{ }^{\circ} \mathrm{C}$ and hold at that. All bio-oil samples produced from the pyrolysis were tested for catalyst performance in terms of bio-oil yield and selectivity.

\section{Results and Discussion}

\subsection{Characterization of the catalyst}

$\mathrm{X}$-ray fluorescence spectroscopy showed $\mathrm{Al}$ dross as a complex oxidic material, was formed when molten aluminum comes in contact with air at the outer surface of the melt. The main constituents of the raw material include $\mathrm{Al}_{2} \mathrm{O}_{3}$, $\mathrm{Cl}, \mathrm{Fe}_{2} \mathrm{O}_{3}$, and $\mathrm{K}_{2} \mathrm{O}$, with almost equal amounts of $\mathrm{CaO}, \mathrm{CuO}$, and $\mathrm{SiO}_{2}$ and small amounts of other metal oxides as shown in Table 1 . The chemical and mineralogical composition of $\mathrm{Al}$ dross depends mainly on the quality of Al scrap processing, the operating conditions, and the type of technology and furnace applied for $\mathrm{Al}$ metal production [14]. The acid washing characterization showed the increasing $\mathrm{Al}_{2} \mathrm{O}_{3}$ content after $\mathrm{HCl}$ washing. This effect could be explained by two reasons as follows. First, prior to acid washing, the raw material was subjected to grinding using a ball mill and subse- 
quent sieving with a $<300 \mu \mathrm{m}$ mesh. According to Hwang et al. [15] and Tsakiridis et al. [14], metallic aluminum could be recovered by screening and sieving after crushing and grinding the original Al dross. Second, Das et al. [7] reported that when $\mathrm{Al}$ dross was subjected to acid treatment with $15 \% \mathrm{H}_{2} \mathrm{SO}_{4}$ concentration, the material recovered alumina at around $71 \%$ yield. Therefore, alumina content increased to $593.59 \mathrm{mg} . \mathrm{g}^{-1}$, when the Al dross was treated with acid at $20 \mathrm{wt} \%$. The chloride content disappeared from the $\mathrm{Al}$ dross after conducting a treatment by Miskufova et al. [16] in which $\mathrm{HCl}$ was adopted to leach out all chloride content. This method was first employed when the groups studied $\mathrm{Al}$ leachability from aluminum dross fines after mechanical pretreatment in alkaline solution at atmospheric conditions.

Table 1. Component analysis of the $\mathrm{Al}$ dross

\begin{tabular}{ccc}
\hline \multirow{2}{*}{$\begin{array}{c}\text { Metal } \\
\text { oxides }\end{array}$} & \multicolumn{2}{c}{ Composition analysis $\left(m g . g^{-1}\right)$} \\
\cline { 2 - 3 } $\mathrm{Al}_{2} \mathrm{O}_{3}$ & 390.97 & 593.59 \\
$\mathrm{Cl}$ & 222.83 & n.d. \\
$\mathrm{Fe}_{2} \mathrm{O}_{3}$ & 124.05 & 149.31 \\
$\mathrm{~K}_{2} \mathrm{O}$ & 96.24 & 17.16 \\
$\mathrm{CaO}$ & 35.71 & 18.72 \\
$\mathrm{CuO}$ & 33.83 & 58.31 \\
$\mathrm{SiO}_{2}$ & 30.07 & 73.13 \\
$\mathrm{ZnO}$ & 16.01 & 19.67 \\
$\mathrm{MnO}$ & 13.15 & 14.52 \\
$\mathrm{TiO}_{2}$ & 9.69 & 11.97 \\
$\mathrm{BaO}_{\mathrm{SO}}$ & 8.70 & 16.78 \\
$\mathrm{Cr}_{3}$ & 5.62 & 11.03 \\
$\mathrm{Cr}_{2} \mathrm{O}_{3}$ & 4.94 & 6.57 \\
$\mathrm{SrO}$ & 3.22 & 2.21 \\
$\mathrm{NiO}$ & 2.68 & 4.33 \\
$\mathrm{Br}$ & 0.87 & n.d. \\
$\mathrm{Ac}$ & 0.79 & 1.4 \\
\hline
\end{tabular}

Note: n.d. $=$ not detected
Table 2 shows the surface area analysis in the raw Al dross (unmodified) and modified material. After acid washing, it was observed a sharp increase in BET surface area and pore volume to $68.24 \mathrm{~m}^{2} / \mathrm{g}$ and $0.34 \mathrm{~cm}^{3} / \mathrm{g}$, respectively. This increase could be due to dissolution of oxidizing deposits which were initially blocking the pore opening. According to the International Union of Pure and Applied Chemistry (IUPAC), Figure 2a shows the adsorptiondesorption of $\mathrm{N}_{2}$ displaying type of isotherm III, indicating the presence of macroporous $(>50 \mathrm{~nm})$ structures. The majority of these structures comprise macroporous regions with low surface areas as shown in Table 2, which means the interaction was very weak with the adsorbent molecules. The isotherm suggests a multilayer adsorption process. The hysteresis loop type H3 reveals a macroporous structure for flaky plate particles; this result is in agreement with the SEM analysis (Figure 3a). On the other hand, the $\mathrm{Al}$ dross material after con-
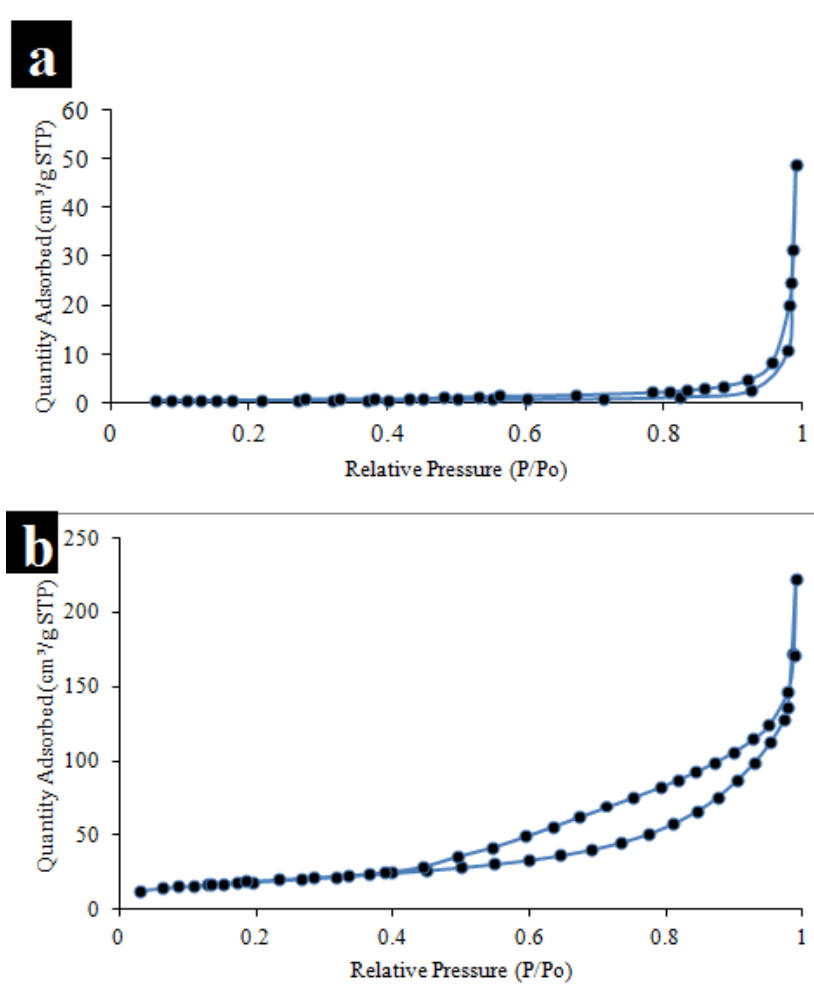

Figure 2. Isotherm of $\mathrm{Al}$ dross (a) raw material and (b) modified material.

Table 2. Pore characteristics of the $\mathrm{Al}$ dross

\begin{tabular}{lcc}
\hline \multicolumn{1}{c}{ Al dross } & Raw material & Acid washing method \\
\hline BET surface area $\left(\mathrm{m}^{2} / \mathrm{g}\right)$ & 0.96 & 68.24 \\
Pore volume $\left(\mathrm{cm}^{3} / \mathrm{g}\right)$ & 0.06 & 0.34 \\
Average pore diameter $(\mathrm{nm})$ & 283.28 & 20.24 \\
\hline
\end{tabular}


ducting acid washing with $\mathrm{HCl}$ shows isotherm $\mathrm{V}$ with hysteresis loop type $\mathrm{H} 1$, indicating an increase mesopore structure through its hysteresis loop, that is, the non-overlapping portion of the adsorption and desorption branches. The SEM image as shown in Figure $3 b$ displays the changes after modification.

Thermogravimetric study was performed to verify the thermal stability of the material. Thermal stability refers to the ability of a substance to resist property changes under heat. The raw material (unmodified) did not show thermal stability (Figure 4a) upon testing. The weight curve sharply plummeted by around $0.7 \%$; such weight loss could be attributed to the loss of water molecules caused by crystallization. However, following the decrease in weight, a subsequent weight increase occurs after the temperature exceeded $520{ }^{\circ} \mathrm{C}$. This increase in weight is likely due to oxidation. By contrast, the acid washing method affords the Al dross good thermal stability as shown in Figure $4 \mathrm{~b}$ because the process triggered the molecules to exhibit higher resistance against decomposition at high temperatures.

The catalyst surface concentrations of acidic centers was measured by temperature programmed desorption of ammonia (TPD-NH 3 ). The TPD spectra of the adsorbed ammonia on the unmodified $\mathrm{Al}$ dross as portrayed in Figure $5 \mathrm{a}$ indicate the presence of medium acid sites

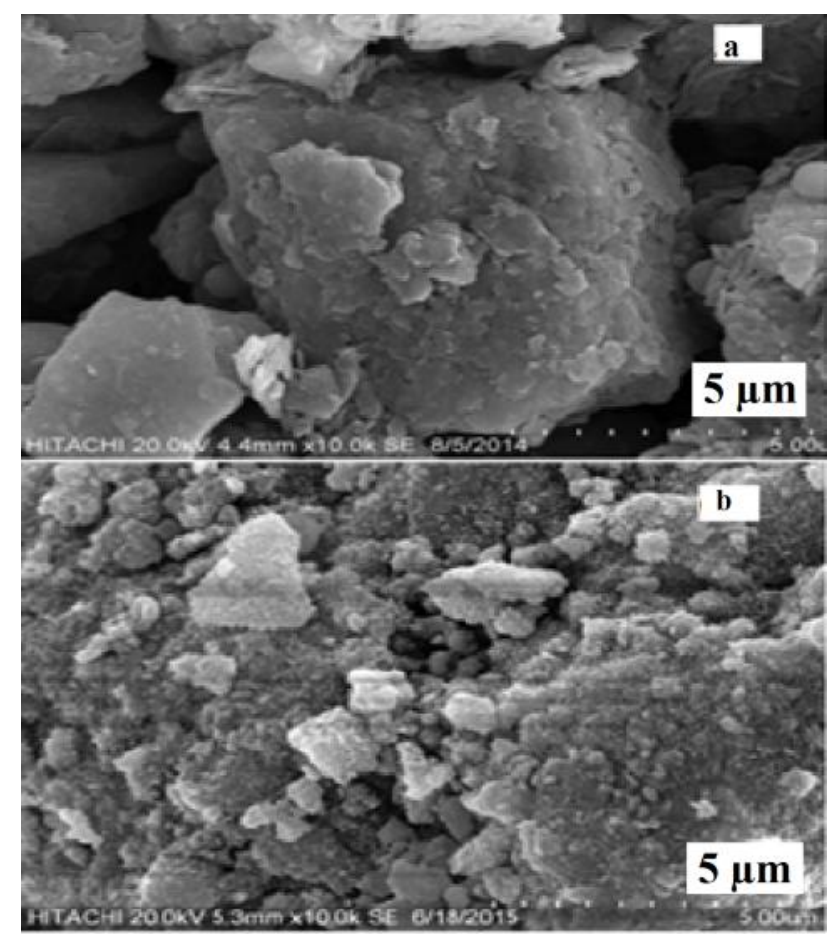

Figure 3. SEM morphology of $\mathrm{Al}$ dross (a) raw material and (b) modified material. with a density of $315 \mu \mathrm{mol} / \mathrm{g}$ at $520^{\circ} \mathrm{C}$. By contrast, after acid washing of the $\mathrm{Al}$ dross with $\mathrm{HCl}$ and calcination for $3 \mathrm{~h}$ at $600{ }^{\circ} \mathrm{C}$, the TPD spectra of the adsorbed ammonia (Figure 5b) show two peaks. The first peak is noted at temperature $321{ }^{\circ} \mathrm{C}$ belongs to weak acid site. Whereas, the second peak at temperature 909 ${ }^{\circ} \mathrm{C}$ exhibits stronger acid site. The total amount of gas adsorbed by the sample is $748 \mu \mathrm{mol} / \mathrm{g}$. The increased acidity of the modified material was due to the enlargement in the surface area and pore volume.

\subsection{Characterization of bio-oil}

\subsubsection{Functional group analysis of bio-oil}

To measure the catalytic performance of the catalyst, both acid-treated and unmodified $\mathrm{Al}$ dross were applied in the pyrolysis of waste cooking oil together. The results were compared with non-catalytic pyrolysis of waste cooking oil as thermal cracking. FT-IR analysis was performed to examine the chemical functional groups present in the bio-oil produced from the pyrolysis. An important observation on the bio-oil is that the composition of the pyrolysis oil resembled that in the original biomass (waste cooking oil) but was drastically different from those in petroleum-derived fuels
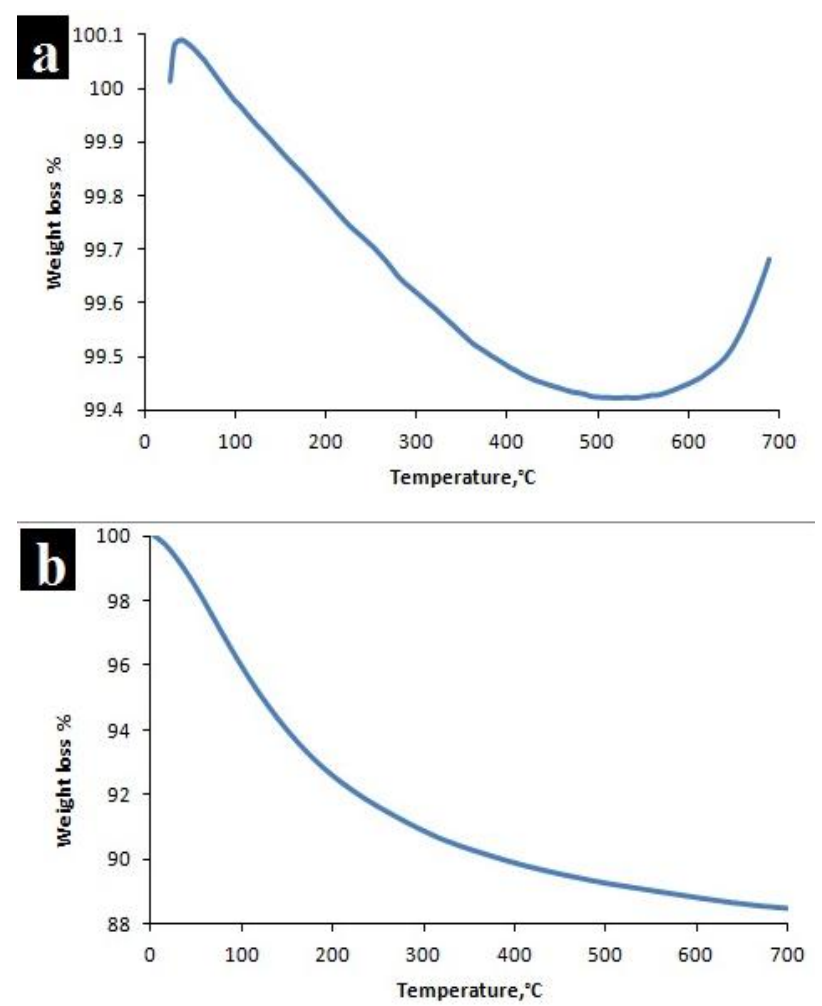

Figure 4. TGA of $\mathrm{Al}$ dross for (a) raw material and (b) modified material. 
[17]. Figure 6 displays the comparison of main functional groups between waste cooking oil and bio-oil produced using $\mathrm{Al}$ dross before and after modification. The pyrolysis oil (bio-oil) shows characteristic vibrational modes at 2850$3000 \mathrm{~cm}^{-1}$ for the $\mathrm{C}-\mathrm{H}$ stretching in alkanes, $1000-1320 \mathrm{~cm}^{-1}$ for the $\mathrm{C}-\mathrm{O}$ stretching in carboxylic acid, 910-950 $\mathrm{cm}^{-1}$ for the $\mathrm{O}-\mathrm{H}$ bending in carboxylic acid, and $720-725 \mathrm{~cm}^{-1}$ for the $\mathrm{C}-\mathrm{H}$ rocking in alkanes $[18,19]$.

An extremely broad absorption peak centering at $1185 \mathrm{~cm}^{-1}$ for the $\mathrm{C}=\mathrm{O}$ stretching in carboxylic acid is observed in the spectra of the waste cooking oil. This peak could be a measure for the progress of deoxygenation cracking reactions. This peak does not present in the cracking products under untreated and treated $\mathrm{Al}$ dross catalyst. The appearance of new peaks

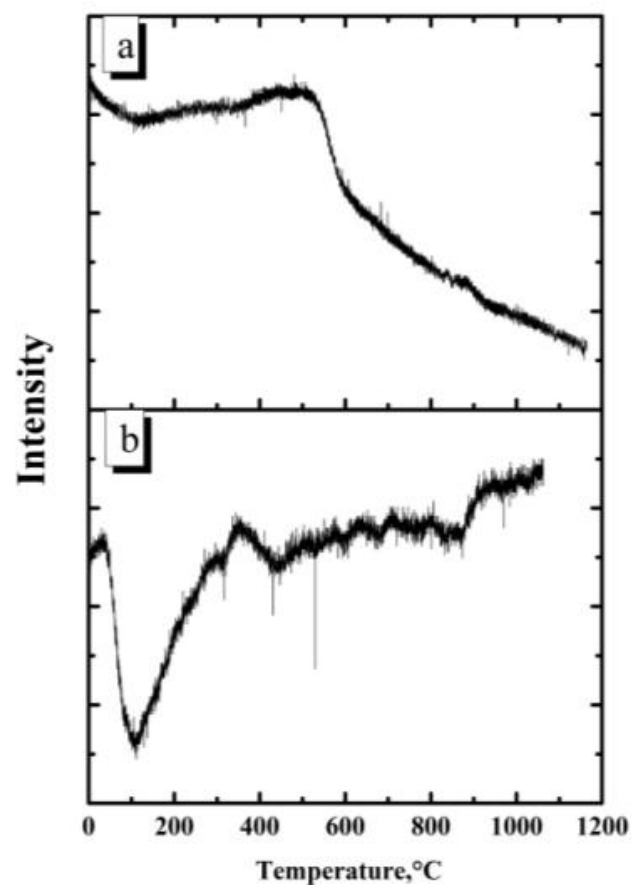

Figure 5. TPD- $\mathrm{NH}_{3}$ analysis for $\mathrm{Al}$ dross (a) raw material and (b) modified material of $\mathrm{C}-\mathrm{O}$ stretching at $1285 \mathrm{~cm}^{-1}$ and $\mathrm{O}-\mathrm{H}$ bending at $910 \mathrm{~cm}^{-1}$ in the bio-oil indicates the presence of carboxylic acid in small amounts. In addition, a slight shift in FT-IR peak $\left(1710 \mathrm{~cm}^{-1}\right)$ in the deoxygenated product denotes the $\mathrm{C}=\mathrm{O}$ of the carboxylic acid group, which is consistent with the findings of Asikin-Mijan et al. [20]. The lower intensity of this band at $1710 \mathrm{~cm}^{-1}$ could be credited to the amount of carboxylic acid decreased after the pyrolysis. The spectrum of functional group based on IR adsorption is tabulated in Table 3.

\subsubsection{Chromatographic analysis of the bio-oil}

The yield of bio-oil produced from catalytic pyrolysis of waste cooking oil showed the increment when using with untreated and modified catalysts compared to thermal cracking as shown in Figure 7. The increase of bio-oil yield could be attributed to metal oxide contained in these materials as shown in the XRF characterization of the waste materials before and after treatment (Table 1). This proves that the catalytic properties of metal oxides become ap-

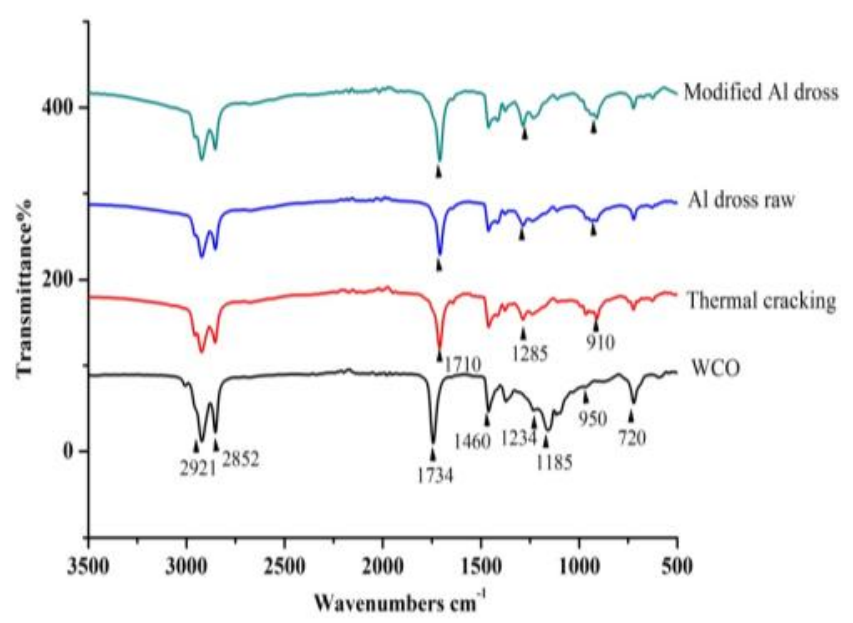

Figure 6. FT-IR spectra of bio-oil produced

Table 3. Summary of characteristic IR absorption for bio-oil.

\begin{tabular}{lcc}
\hline Functional groups & $\begin{array}{c}\text { Vibration modes range } \\
\left(\mathbf{c m}^{-1}\right)\end{array}$ & $\begin{array}{c}\text { Bio-oil characteristic ab- } \\
\text { sorption peaks }\left(\mathbf{c m}^{-1}\right)\end{array}$ \\
\hline C-H stretch & $2800-3000$ & 2852,2921 \\
C=O stretch & $1600-1750$ & 1710,1743 \\
C-H bend & $1350-1470$ & 1372,1460 \\
C-O stretch & $1000-1320$ & $1185,1234,1285$ \\
O-H bend & $910-950$ & 910,950 \\
C-H rock & $720-725$ & $721,722,723$ \\
\hline
\end{tabular}


parent from the adsorption of reactants on the unsaturated metal sites and/or oxygen atom, followed by addition or elimination of hydrogen and/or oxygen [8]. The bio-oil yield produced from catalytic cracking by untreated and treated $\mathrm{Al}$ dross was 14 and $16 \%$, respectively. The slight increase in the bio-oil yield could be ascribed to higher BET surface area (Table 2) and acidity to $748 \mu \mathrm{mol} / \mathrm{g}$ of treated $\mathrm{Al}$ dross. In addition, the increase in the amount of aluminum oxide $\left(\mathrm{Al}_{2} \mathrm{O}_{3}\right)$ contained in $\mathrm{Al}$ dross after acid washing as shown in XRF (Table 1) might contribute to the slight increment of the bio-oil yield. Some studies on pyrolysis of canola oil and sunflower oil using aluminum oxide as catalyst proved the increment in the bio-oil yield [21,22].

For obtaining a detailed understanding of the selectivity of each catalyst toward n-alkane and n-alkene obtained from the catalytic pyrolysis, the composition was analyzed by GC analysis. Figure 8 shows the bio-oil compounds grouped according to their carbon number. It can be seen the bio-oil produced at $390-420{ }^{\circ} \mathrm{C}$, are a mixture of $\mathrm{C}_{7}-\mathrm{C}_{20}$. The figure shows significant change between pyrolysis with raw material (untreated) and modified (treated) $\mathrm{Al}$ dross in the selectivity to carbon number. Pyrolysis with untreated Al dross shows sharp peak at $\mathrm{C}_{7}$, whereas acid-treated $\mathrm{Al}$ dross selected to $\mathrm{C}_{9}$ and $\mathrm{C}_{15}$. Even though only slight increment of bio-oil yield was obtained from the pyrolysis of waste cooking oil using untreated and treated $\mathrm{Al}$ dross, different selectivity of the product was observed. This difference might correlate to increase BET surface area and acidity.

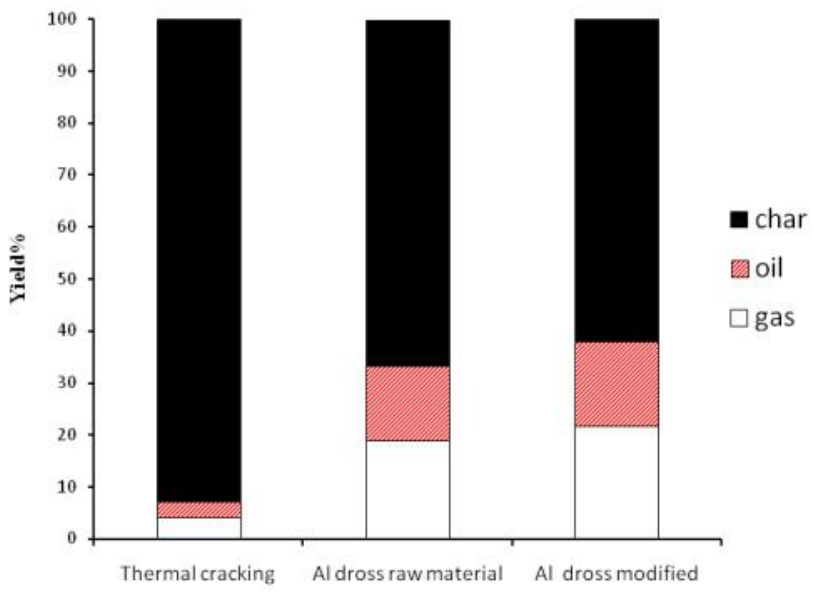

Figure 7. Yield percentage of bio-oil from catalytic pyrolysis

\section{Conclusions}

The characterization of Malaysian $\mathrm{Al}$ dross reveals that this an inexpensive waste material contains precious amount of metal oxides which exhibit cheap source as catalyst. However, several characterization analyses such as surface area, morphology of the surface, thermal stability and acidity showed poor properties of the $\mathrm{Al}$ dross. A simple chemical activation by acid washing method changed most properties of the material. An increase in surface area and acidity enabled $\mathrm{Al}$ dross as potential catalyst candidate in catalytic reactions. The performance of the material in pyrolysis of waste cooking oil proved modified $\mathrm{Al}$ dross represent as a good candidate in the cracking reaction.

\section{Acknowledgement}

The authors acknowledge the financial support from Ministry of Higher Education Malaysia for Fundamental Research Grant Scheme (FRGS/11/TK/UPM/02).

\section{References}

[1] Bennet, J., Lee, A.F., Wilson, K. (2016). Catalytic Applications of Waste Derived Materials. Journal of Materials Chemistry A, 4: 3617-3637.

[2] Murayama, N., Maekawa, I., Ushiro, H., Miyoshi, T., Shibata, J., Valix, M. (2012). Synthesis of Various Layered Double Hydroxides using Aluminum Dross Generated in Aluminum Recycling Process. International Journal of Mineral Processing, 110-111: 46-52.

[3] David, E., Kopac, J. (2013). Aluminum Recovery as a Product with High Added Value using Aluminum Hazardous Waste. Journal of Hazardous Materials, 261: 316-324.

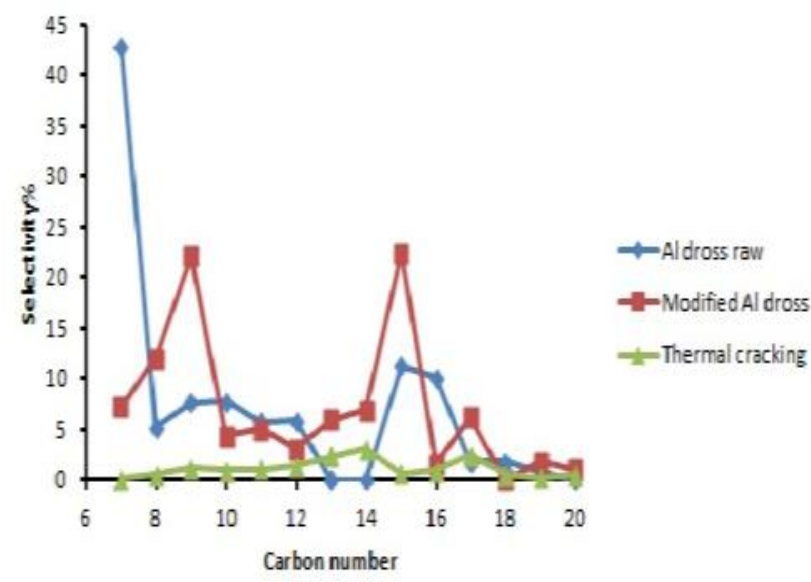

Figure 8. Selectivity of carbon number for $\mathrm{Al}$ dross 
[4] Jafari, N.H., Stark, T.D., Roper, R. (2014). Classification and Reactivity of Secondary Aluminum Production Waste. Journal of Hazardous, Toxic, and Radioactive Waste, 18: 111.

[5] Balakrishnan, M., Batra, V.S., Hargreaves, J.S., Pulfordb, I.D. (2011). Waste Materials Catalytic Opportunities: An Overview of the Application of Large Scale Waste Materials as Resources for Catalytic Applications. Green Chemistry, 13(1): 16-24.

[6] Kim, J., Biswas, K., Jhon, K.W., Jeong, S.Y., Ahn, W.S. (2009).Synthesis of $\mathrm{AlPO}_{4}{ }^{-5}$ and

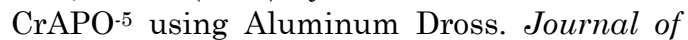
Hazardous Materials, 169(1-3): 919-925.

[7] Das, B.R., Dash, B., Tripathy, B.C., Bhattacharya, I.N., Das, S.C. (2007). Production of gAlumina from Waste Aluminium Dross. Minerals Engineering, 20: 252-258.

[8] Yigezu, Z.D., Muthukumar, K. (2014). Catalytic Cracking of Vegetable Oil with Metal Oxides for Biofuel Production. Energy Conversion and Management, 84: 326-333.

[9] Prado, C.M.R., Filho, N.R.A. (2009). Production and Characterization of the Biofuels Obtained by Thermal Cracking and Thermal Catalytic Cracking of Vegetable Oils. Journal of Analytical and Applied Pyrolysis, 86(2): 338-347.

[10] Karimi, E., Briens, C., Berruti, F., Moloodi, S., Tzanetakis, T., Thomson, M.J., Schlaf, M. (2010). Red Mud as a Catalyst for the Upgrading of Hemp-Seed Pyrolysis Bio-Oil. Energy and Fuels, 24(12): 6586-6600.

[11] Kar, Y., Gurbuz, Z. (2016). Application of Blast Furnace Slag as a Catalyst for Catalytic Cracking of Used Frying Sunflower Oil. Energy Exploration \& Exploitation, 34(2): 262272.

[12] Lu, Q., Zhang, Z.F., Dong, C.Q., Zhu, X.F. (2010). Catalytic Upgrading of Biomass Fast Pyrolysis Vapors with Nano Metal Oxides: An Analytical Py-GC/MS Study. Energies, 3(11): 1805-1820.

[13] Romero, M.J.A., Pizzi, A., Toscano, G., Bosio, B., Arato, E. (2014). Study of an Innovative Process for the Production of Biofuels using Non-Edible Vegetable Oils. Chemical Engineering Transactions, 37(2013): 883-888.
[14] Tsakiridis, P.E., Oustadakis, P., AgatziniLeonardou, S. (2013). Aluminium Recovery during Black Dross Hydrothermal Treatment. Journal of Environmental Chemical Engineering, 1(1-2): 23-32.

[15] Hwang, J.Y., Huang, X., Xu, Z. (2006). Recovery of Metals from Aluminum Dross and Saltcake. Journal of Minerals and Materials Characterization and Engineering, 5(1): 4762.

[16] Miskufova, A., Petranikova, M., Kovacs, M., Briancin, J., Havlik, T., Orac, D. (2009). Leaching of Aluminium Dross in Alkaline Solution. In Proceedings of the European Metallurgical Conference, 24: 1-11. Innbruck, Austria: European Metallurgical Conference EMC2009.

[17] Maher, K.D., Bressler, D.C. (2007). Pyrolysis of Triglyceride Materials for the Production of Renewable Fuels and Chemicals. Bioresoures Technolology, 98(12): 2351-2368.

[18] Putun, A.E., Ozean, A., Putun, E. (1999). Pyrolysis of Hazelnut Shells in a Fixed-Bed Tubular Reactor: Yields and Structural Analysis of Bio-Oil. Journal of Analytical and Applied Pyrolysis, 52(1): 33-49.

[19] Tanneru, S.K., Steele, P.H. (2015). Production of Liquid Hydrocarbons from Pretreated Bio-Oil via Catalytic Deoxygenation with Syngas. Renewable Energy, 80: 251-258.

[20] Asikin-Mijan, N., Taufiq-Yap, Y.H., Lee, H.V. (2015). Synthesis of Clamshell Derived $\mathrm{Ca}(\mathrm{OH})_{2}$ Nano-Particles via Simple Surfactant-Hydration Treatment. Chemical Engineering Journal, 262: 1043-1051.

[21] Vonghia, E., Boocock, D.G.B., Konar, S.K., Leung, A. (1995). Pathways for the Deoxygenation of Triglycerides to Aliphatic Hydrocarbons over Activated Alumina. Energy and Fuels, 9(7): 1090-1096.

[22] Demirbas, A. (2009). Gasoline-Rich Liquid from Sunflower Oil by Catalytic Pyrolysis with Alumina-Treated Sodium Hydroxide. Energy Sources, Part A: Recovery, Utilization, and Environmental Effeccts, 31(8): 671-678. 